\title{
Bridgehead carboxy-substituted 2,3-diazabicyclo[2.2.2]oct-2-enes: synthesis, fluorescent properties, and host-guest complexation
}

\author{
Andreas Hennig, Thomas Schwarzlose, and Werner M. Nau* \\ School of Engineering and Science, Jacobs University Bremen, Campus Ring 1, D-28759 \\ Bremen, Germany \\ E-mail:w.nau@iu-bremen.de
}

Dedicated to Prof. Waldemar Adam on the occasion of his 70th birthday

\begin{abstract}
Two novel derivatives of 2,3-diazabicyclo[2.2.2] oct-2-ene were synthesized, carrying a carboxyl (4) and a methylcarboxyl (5) substituent at the bridgehead position. The photodecomposition quantum yields (51\% for 4 and 2.9\% for 5) and fluorescence lifetimes ( 29 ns for 4 and 345 ns for 5) in water were determined. The higher photoreactivity and fluorescence quenching for 4 was attributed to its higher propensity to undergo photochemical elimination of nitrogen as a consequence of the presence of the radical-stabilizing carboxyl group in the $\alpha$-position. The absolute photodecomposition rate constants of $\mathbf{4}$ became faster upon protonation (e.g., at $\mathrm{pH}$ 2), which contrasted anticipated substituent effects on the $\mathrm{C}-\mathrm{N}$ bonds strengths. The complexation behavior of both acids, 4 and 5, with tetrakis $(N, N$ '-dimethylammoniomethyl)tetrahydroxycalix[4]arene (17) and $\beta$-cyclodextrin was studied by fluorescence and induced circular dichroism, respectively, in order to evaluate their suitability as potential sensor systems for anions and analytes with hydrogen-bonding abilities, respectively. The binding constants of $\mathbf{4}$ and 5 with the calixarene 17 were unexpectedly small $\left(<2000 \mathrm{M}^{-1}\right)$ which was attributed to reduced Coulomb attractions as a consequence of the 1,3-alternate conformation which this host adopts in water. The binding constants towards $\beta$-cyclodextrin were also low at pH $7.0\left(<120 \mathrm{M}^{-1}\right)$, which was attributed to the low hydrophobicity of the anionic form of the guests; in line with this interpretation, the binding constants with $\beta$-cyclodextrin increased at $\mathrm{pH}$ 2.0 , by about one order of magnitude.
\end{abstract}

Keywords: Photochemistry, azoalkanes, fluorescence, calixarenes, cyclodextrins 


\section{Introduction}

Azoalkanes are prone to eliminate nitrogen both thermally and photochemically. ${ }^{1-3}$ They have remained key intermediates in the synthesis of strained compounds ${ }^{1,4}$ and in the mechanistic investigation of the behavior of biradicals, ${ }^{5-11}$ with some seemingly never-ending mechanistic disputes like the double-inversion peculiarity of 2,3-diazabicyclo[2.2.1]hept-2-enes. ${ }^{12,13}$ Derivatives of 2,3-diazabicyclo[2.2.2]oct-2-ene (DBO, 1) have recently become valuable structural and dynamic probes ${ }^{14}$ as well as sensors for supramolecular ${ }^{15-23}$ and biomolecular assemblies. ${ }^{23-35}$ Until now, the derivatives with 1-hydroxymethyl (2) ${ }^{23-26}$ and 1-aminomethyl groups $(\mathbf{3})^{30}$ have been employed as key precursors for subsequent derivatization, e.g., for the introduction into polypeptides, ${ }^{30-35}$ polynucleotides, ${ }^{24}$ or biomembranes ${ }^{26-29}$ Herein, we describe the DBO carboxylic acid $\mathbf{4}$ and the DBO acetic acid $\mathbf{5}$. We synthesized these derivatives for two main reasons: First, we wanted to broaden the repertoire of available derivatives for subsequent biolabeling, e.g., $N$-hydroxysuccinimid (NHS) esters are popular compounds for post-column peptide labeling of amino groups, and secondly, we were interested in the effects of a negative charge on the complexation of the DBO chromophore with macrocyclic host molecules, with the ultimate perspective to design refined sensor applications. ${ }^{36}$ Herein, we describe the synthesis of 4 and 5, the photophysical and photochemical characterization of both acids, including some unexpected peculiarities, and their complexation behavior with $\beta$-cyclodextrin and positively charged calix[4]arenes.

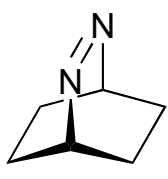

1

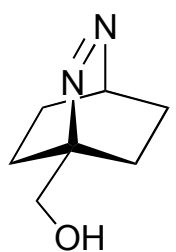

2

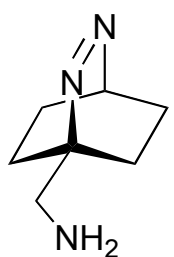

3

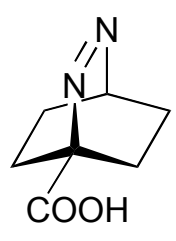

4

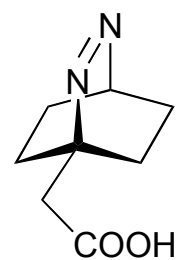

5

\section{Results and Discussion}

\section{Synthesis}

The synthesis of DBO was first reported in 1962 by Cohen and Zand ${ }^{37}$ and since then many derivatives have been prepared owing to their interesting photophysical properties. In fact, Adam $^{38}$ and others ${ }^{39-42}$ already studied more complex polycyclic derivatives carrying bridgehead carboxyl substituents, e.g. derivative $\mathbf{6}$, which can be obtained under mild acid-catalyzed conditions from the reaction of 4,5-dihydropyridazines with electron-rich alkenes (the SauerHünig route to polycyclic azoalkanes). ${ }^{43,44}$ Moreover, Engel and coworkers synthesized the DBO derivative 7 carrying a carboxyl group in the 5 endo position, ${ }^{41}$ which is obtained under the harsh 
hydrolysis conditions of the urazole route (heating in concentrated base). ${ }^{41}$ In contrast, the simple bridgehead carboxyl derivative $\mathbf{4}$ has remained unknown.

Unfortunately, the known derivatives, like 6 and 7, are entirely unsuitable for the desired applications in biomolecular and supramolecular chemistry. On one hand, DBO derivatives are frequently preferred due to their high hydrophilicity and small size, which is not fulfilled for derivative 6; in addition, the presence of two functional groups in $\mathbf{6}$ (rather than a single carboxyl group) is most undesirable for biomolecular labeling purposes. On the other hand, derivative 7 is obtained as a racemic mixture, which would lead to the formation of two diastereomers in the labeling of biomolecules, in particular polypeptides, or in the molecular recognition with chiral hosts like cyclodextrins. ${ }^{18,23}$ Such diastereomeric complications need to be avoided at all cost, in particular in mechanistic investigations.

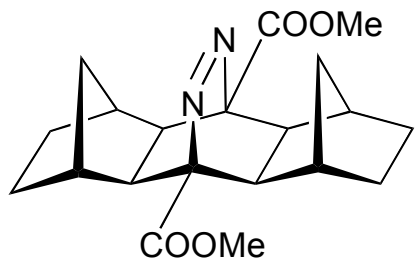

6

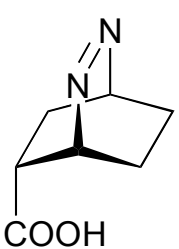

7

To by-pass the above problems, while maintaining high water-solubility, we have previously synthesized and comprehensively employed the derivatives 2 and 3. ${ }^{14,23-26,30}$ Several attempts to oxidize the hydroxymethyl DBO 2 directly to the bridgehead carboxy-substituted derivative 4 by several mild oxidation methods failed, such that we needed to resort to the conventional synthesis route based on cycloaddition with 4- $N$-methyl-1,2,4-triazolin-3,5-dione (MTAD, Scheme 1). ${ }^{1}$

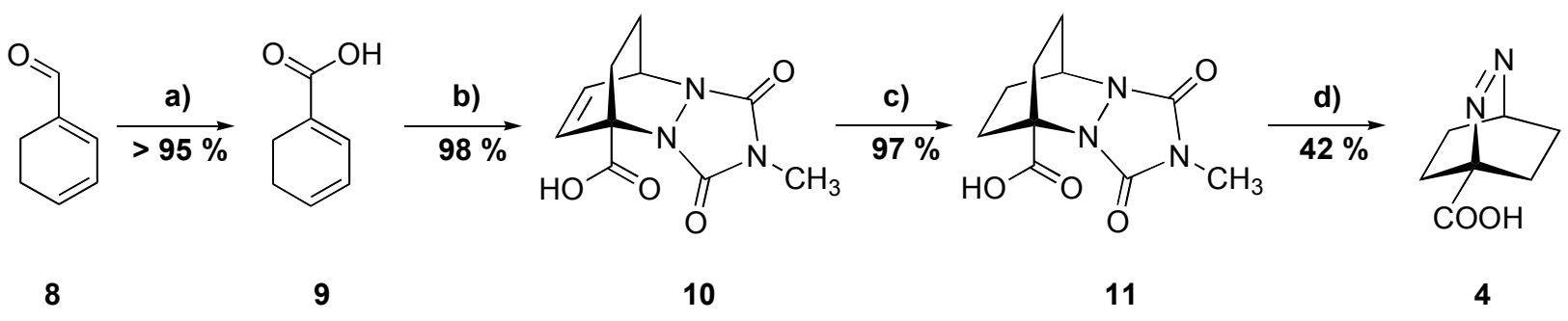

Scheme 1. Synthesis of the DBO carboxylic acid 4. Conditions used: a) $\mathrm{Ag}^{+}$in $\mathrm{H}_{2} \mathrm{O} / \mathrm{THF}$ for 16 $\mathrm{h}$, b) MTAD in $\mathrm{CH}_{2} \mathrm{Cl}_{2}$ at $0{ }^{\circ} \mathrm{C}$, c) hydrogenation with $\mathrm{Pd} / \mathrm{C}$ in ethanol for $16 \mathrm{~h}$, d) $\mathrm{KOH}$ in $i$ propanol at $80{ }^{\circ} \mathrm{C}$ for 2 days, subsequent standing under air for 3 days.

The cycloaddition with MTAD required cyclohexa-1,3-dienecarboxylic acid (9), which had been previously obtained by a different route. ${ }^{45}$ We obtained 9 in excellent yield from the readily accessible $^{44}$ cyclohexa-1,3-dienecarbaldehyde $(\mathbf{8})$ by ambient-temperature oxidation ${ }^{46}$ with 
freshly precipitated silver hydroxide in a THF/water-mixture; as a minor oxidation by-product, benzoic acid $(<5 \%$, depending on reaction time and concentration) was identified. Since the latter was not expected to interfere with the following cycloaddition reaction with MTAD, we used the crude oxidation product. The cycloaddition with MTAD proceeded smoothly at ambient temperature, with the usual white-to-pink color change as a convenient indicator for complete conversion; however, the urazole $\mathbf{1 0}$ precipitated partially due to its limited solubility in the dichloromethane solvent. Benzoic acid, which presented an impurity from the preceding oxidation step, was removed by the subsequent recrystallization of $\mathbf{1 0}$ from ethanol. The low solubility of $\mathbf{1 0}$ in ethanol precluded also the subsequent use of this solvent in the hydrogenation step. Dioxane was selected as an alternative, and the hydrogenation (ambient temperature, $1 \mathrm{~atm}$ ) proceeded quantitatively as well. The product was extensively purified by several recrystallizations from $i$-propanol, because the purity was deemed an essential factor for the success of the subsequent hydrolysis to produce 4 .

Commonly, oxidation of the hydrazine, as the initial urazole hydrolysis product, to the azoalkane can be effected in-situ by carrying out the hydrolysis under air. ${ }^{47}$ To prepare azoalkane 4, however, we found a cleaner reaction when we separated the hydrolysis step from the oxidation by carrying it out under inert atmosphere. In addition, the hydrolysis time needed to be prolonged significantly ( 2 days) to affect higher conversion in larger scales. Subsequently, the hydrolyzed product (hydrazine) was given 3 days to oxidize under air. The highly water-soluble product 4 was obtained by acidification and recrystallization from ethyl acetate in $42 \%$ yield. We suspected first that a thermal instability of $\mathbf{4}$ was responsible for the moderate yield in this reaction. Note that azoalkanes with tertiary $\alpha$-carbons and at least one radical-stabilizing substituent (with azo isobutyronitrile, AIBN, being the prototypal example), are known to decompose readily even at only slightly elevated temperature. ${ }^{48,49}$ However, control experiments showed that compound 4 was thermally stable for at least $72 \mathrm{~h}$ even in water at $95{ }^{\circ} \mathrm{C}$ (no decomposition observed by UV).

The DBO acetic acid 5 was prepared according to Scheme 2. Nucleophilic substitution of the previously reported ${ }^{30}$ tosylate $\mathbf{1 2}$ is known to be unfavorable due to the steric hindrance imposed by the neopentyl-type position; in the preparation of $\mathbf{3}$ (azide substitution with subsequent reduction) the use of sodium azide in HMPT at elevated temperature for $14 \mathrm{~h}$ was required. ${ }^{30}$ For the preparation of azoalkane 5 (cyanide substitution with subsequent alkaline hydrolysis), the higher nucleophilicity of cyanide ${ }^{50}$ allows one to avoid the highly toxic HMPT, because already the use of an excess of sodium cyanide in dry DMSO at $110^{\circ} \mathrm{C}$ for $24 \mathrm{~h}$ led to the formation of nitrile 13. The subsequent hydrolysis to 5 proceeded smoothly. 


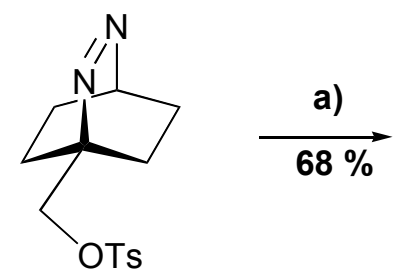

12

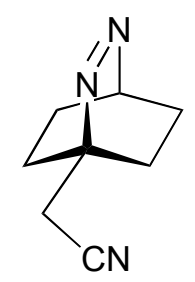

13
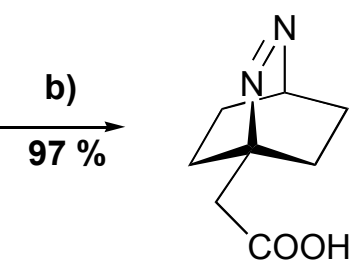

5

Scheme 2. Synthesis of DBO acetic acid 5. Conditions used: a) $\mathrm{NaCN}$ in DMSO at $110{ }^{\circ} \mathrm{C}$ for $24 \mathrm{~h}$, b) $\mathrm{NaOH}$ in $\mathrm{H}_{2} \mathrm{O} / \mathrm{EtOH}$ at $90{ }^{\circ} \mathrm{C}$ for $16 \mathrm{~h}$.

Table 1. Selected photophysical properties of azoalkanes $\mathbf{1},{ }^{[1]} \mathbf{4}$, and $\mathbf{5}$ in aerated $\mathrm{H}_{2} \mathrm{O}$

\begin{tabular}{ccccccl}
\hline Azoalkane & $\mathrm{pH}$ & $\lambda_{\max } / \mathrm{nm}$ & $\varepsilon /\left(\mathrm{cm}^{-1} \mathrm{M}^{-1}\right)$ & $\tau / \mathrm{ns}$ & $\Phi_{\mathrm{f}}^{[2]}$ & \multicolumn{1}{c}{$\Phi_{\mathrm{r}}^{[3]}$} \\
\hline $\mathbf{1}$ & 7.0 & 365 & 48 & $325^{[4]}$ & 0.20 & 0.003 \\
$\mathbf{4}$ & 7.0 & 367 & 51 & $29[32]^{[5]}$ & 0.02 & 0.51 \\
& 2.0 & 364 & 49 & $5.4[6.4]^{[5]}$ & 0.003 & 0.53 \\
$\mathbf{5}$ & 7.0 & 366 & 57 & $345^{[4]}$ & 0.21 & 0.029 \\
\hline
\end{tabular}

${ }^{[1]}$ From ref. ${ }^{22,51,52}$. ${ }^{[2]}$ Fluorescence quantum yield, estimated from the relative fluorescence lifetimes with reference to $\mathbf{1}\left(\Phi_{\mathrm{f}}=0.20\right) .{ }^{52}{ }^{[3]}$ Photodecomposition quantum yield, determined with reference to $1\left(\Phi_{\mathrm{r}}=0.003\right) ;{ }^{52} 10 \%$ error. ${ }^{[4]}$ No dependence on $\mathrm{pH} .{ }^{[5]}$ Values in square brackets refer to $\mathrm{D}_{2} \mathrm{O}$ as solvent, $\mathrm{pD} 2.3$ and 7.0.

\section{Photophysical characterization}

Azoalkanes have attracted much attention throughout recent years due to their diverse photochemistry. ${ }^{1-13,38,41,48,53,54}$ DBO and its derivatives are special examples, because many of them are photochemically "persistent" azoalkanes, which show fascinating photophysical properties instead. ${ }^{3,38,52,55}$ Besides an unexpectedly short phosphorescence lifetime, ${ }^{41}$ DBO exhibits a very broad fluorescence spectrum ${ }^{52}$ and an exceedingly long fluorescence lifetime (up to $1 \mu \mathrm{s}$ in the gas phase). ${ }^{52}$ The latter feature has been observed for most DBO derivatives (1-3, as well as alkyl and dichloro-substituted derivatives $)^{22,53}$ and applies also to the novel acetic acid $5(\tau=345 \mathrm{~ns}$, Table 1$)$.

In sharp contrast stands the carboxylic acid 4 , which has a relatively short fluorescence lifetime ( $\tau=29 \mathrm{~ns}$ at $\mathrm{pH}>5$, Table 1$)$. Such short fluorescence lifetimes are already known for some DBO derivatives, namely those carrying carboxylic acid ester, phenyl, or vinyl groups in the bridgehead positions. ${ }^{38,53}$ A specific example is the 1-phenyl derivative 14. It was concluded that these substituents decrease the activation energy and accelerate the rate of nitrogen extrusion by stabilizing the incipient carbon radical site. ${ }^{38,48,53,56}$ This affects also the quantum yield of photodecomposition $\left(\phi_{\mathrm{r}}\right)$, which we have consequently determined ${ }^{57}$ in water as solvent with reference to the parent $1\left(\phi_{\mathrm{r}}=0.003\right) .{ }^{17} \mathrm{We}$ found that the photodecomposition quantum yield was only slightly enhanced for $5\left(\phi_{\mathrm{r}}=0.029\right)$, but much higher for $4\left(\phi_{\mathrm{r}}\right.$ ca. 0.5$)$. The results are 
in accord with literature data, which predict ${ }^{10,56,58,59}$ a less efficient radical stabilization by a carboxylic acid substituent than, for example, by a phenyl substituent. In fact, azoalkane $\mathbf{1 4}$ decomposes with unit quantum efficiency ( $\phi_{\mathrm{r}}=1.0$, in benzene) ${ }^{53,56,58}$

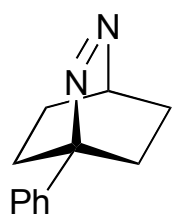

14

The resonance-stabilizing effect of a substituent is also reflected in the product distribution of azoalkanes photolysis. The commonly observed photoproducts of DBO derivatives are 1,5hexadienes and bicyclo[2.2.0]hexanes; the yield of the former photoproduct is assumed to increase with the delocalizing ability of the substituents, because of the general driving force to form a larger conjugated system. ${ }^{53}{ }^{1} \mathrm{H}$ NMR analysis (without isolation of the individual products) of the photolysis products from 4 revealed 2-methylenehex-5-enoic acid $15^{60,61}$ and the bicyclo[2.2.0] hexane-1-carboxylic acid $\mathbf{1 6}^{62}$ in a product ratio of $\sim 90: 10$. For comparison, the conjugation with a phenyl group in $\mathbf{1 4}$ produces solely 2-phenyl-1,5-hexadiene (in benzene), ${ }^{53}$ while the parent 1 produces ca. $70 \%$ hexadiene and 30\% bicyclo[2.2.0] hexane (in water). ${ }^{17}$

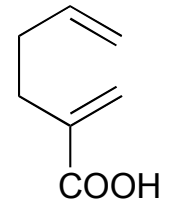

15

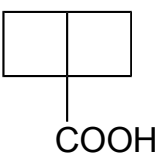

16

The photophysical properties of azoalkanes $\mathbf{4}$ and $\mathbf{5}$ were determined by UV absorption as well as steady-state and time-resolved fluorescence spectroscopy in aerated water at $\mathrm{pH} 7.0$ (Table 1). The fluorescence lifetime of 5 (345 ns) can be considered as "unquenched" in comparison to the parent $\mathbf{1}(325 \mathrm{~ns}) .{ }^{17} \mathrm{In}$ contrast, the fluorescence lifetime of $\mathbf{4}(29 \mathrm{~ns}$ at $\mathrm{pH}>5)$ is much shorter, which is an expected manifestation of its ca. 15 times larger photodecomposition quantum yield (vide supra); for comparison, the 1-phenyl derivative 14, which eliminates nitrogen photochemically with unit quantum efficiency, is virtually nonfluorescent and has a very short $(2.5 \mathrm{~ns})$ fluorescence lifetime. ${ }^{53}$ The relative fluorescence intensities showed the same trends as the fluorescence lifetimes, as expected, while the UV absorption spectra revealed only very minor shifts as a consequence of the bridgehead substitution (Table 1).

The high water solubility of azoalkane 4 in both its protonated (carboxylic acid) and unprotonated (carboxylate) forms allowed us also to perform $\mathrm{pH}$-dependent studies. In detail, we measured the quantum yields for photodecomposition $\left(\Phi_{\mathrm{r}}\right.$, Table 1$)$ and the fluorescence lifetimes ( $\tau$, Table 1) at $\mathrm{pH} 7$ and 2 in order to determine the absolute photochemical reaction rates $\left(k_{\mathrm{r}}=\Phi_{\mathrm{r}} / \tau\right)$. We found that photochemical nitrogen extrusion in $\mathbf{4}$ proceeds 5-6 times faster 
at $\mathrm{pH} 2\left(k_{\mathrm{r}}=9.8 \times 10^{7} \mathrm{~s}^{-1}\right)$ than at $\mathrm{pH} 7\left(k_{\mathrm{r}}=1.8 \times 10^{7} \mathrm{~s}^{-1}\right)$. This reactivity pattern contrasts expectations from substituent effects on the bond dissociation energies of the $\mathrm{C}-\mathrm{N}$ bond to be broken during the photochemical reaction. For example, $\mathrm{C}-\mathrm{H}$ bond dissociation energies are higher for acetic acid $(95.3 \mathrm{kcal} / \mathrm{mol})$ than in the acetate anion $(93.7 \mathrm{kcal} / \mathrm{mol}){ }^{63}$ This trend was also reproduced by semi-empirical calculations (UHF-AM1) for the two prototropic forms of azoalkanes 4 , which revealed also a $0.9 \mathrm{kcal} / \mathrm{mol}$ lower $\mathrm{C}-\mathrm{N}$ bond dissociation energy for the anionic form, suggesting again that protonation of the carboxylic acid group at $\mathrm{pH} 2$ should slow denitrogenation, and not accelerate it as experimentally observed. Obviously, the photoinduced bond cleavage in $\mathbf{4}$ is governed by additional factors, presumably polar effects on the transitionstate.

The difference in photochemical reactivity accounts also directly for the strong fluorescence quenching observed for both steady-state intensities and lifetimes of azoalkane $\mathbf{4}$ when we lowered the $\mathrm{pH}$ from 7 to 2 (see Figure 1). The quenching was somewhat more pronounced in the steady-state (factor ca. 10) than in the time-resolved (factor ca. 6) measurements. The fact that the largest change occurred near the typical $\mathrm{p} K_{\mathrm{a}}$ values of carboxylic acids (ca. 4) demonstrated nicely that the protonation of the carboxylic acid group was responsible for the fluorescence quenching. For comparison, absorption spectra remained virtually unchanged down to $\mathrm{pH} 1.5$, which confirmed that no protonation of the azo chromophore had occurred in the relevant low $\mathrm{pH}$ range; ${ }^{15}$ also the fluorescence intensities and lifetimes of the parent $\mathbf{1}$ remain unaffected in this $\mathrm{pH}$ range. ${ }^{32}$

a)

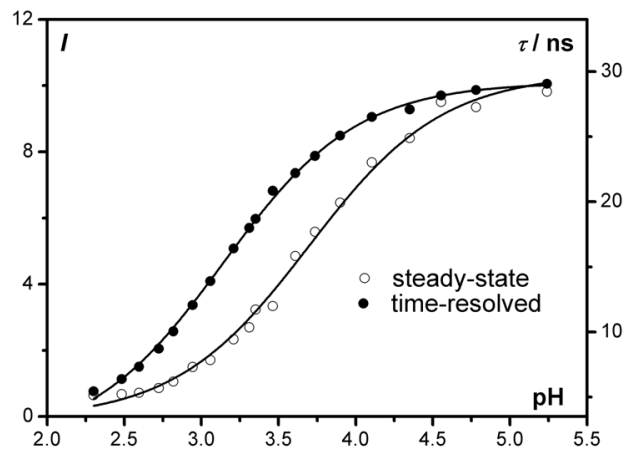

b)

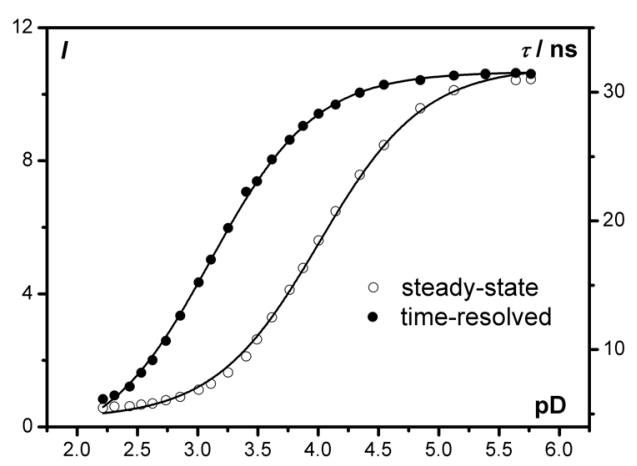

Figure 1. $\mathrm{pH}$ titration curves of 4 in a) $\mathrm{H}_{2} \mathrm{O}$ and b) $\mathrm{D}_{2} \mathrm{O}$ by steady-state (open circles, left scale) and time-resolved fluorescence spectroscopy (filled circles, right scale).

The fluorescence quenching is clearly due to an intramolecular process, i.e., photochemical reaction. Intermolecular quenching was readily excluded by the fluorescence lifetimes, which were independent of fluorophore concentration in the range of 0.1-1 mM; in addition, we remeasured the fluorescence lifetimes of $\mathbf{1}$ in degassed acetic acid and observed rather long fluorescence lifetimes and consequently inefficient intermolecular quenching by carboxylic acid groups ( $\tau=220 \mathrm{~ns}, k_{\mathrm{q}}=3.6 \times 10^{6} \mathrm{~s}^{-1}$, this work, calculated with reference to an unquenched (gas phase) fluorescence lifetimes of $\left.\tau_{0}=1030 \mathrm{~ns}\right),{ }^{64}$ as observed previously. ${ }^{52}$ However a deuterium 
isotope effect of $\sim 3.6$ for the solvent-induced quenching by acetic acid (acetic acid-d1, $\tau=490$ ns, $k_{\mathrm{q}}=1.1 \times 10^{6} \mathrm{~s}^{-1}$, this work) was also established, which suggests that a carboxylic acid substituent does nevertheless act as a weak quencher (hydrogen atom donor). Its main influence on the photophysical properties of $\mathbf{4}$ is, however, manifested in the acceleration of its photodecomposition, which reveals also an interesting $\mathrm{pH}$ dependence (vide supra).

Another interesting peculiarity of $\mathbf{4}$ is the observed difference in $\mathrm{p} K_{\mathrm{a}}$ values derived from the steady-state and time-resolved fluorescence titrations (see Figure 1). This variation is not yet understood, but presumably due to additional protonation equilibria in the excited-state. The $\mathrm{p} K_{\mathrm{a}}$ value as determined by time-resolved-fluorescence is $\sim 3.1$ in $\mathrm{D}_{2} \mathrm{O}$ as well as in $\mathrm{H}_{2} \mathrm{O}$. However, the $\mathrm{p} K_{\mathrm{a}}$ value as determined by steady-state fluorescence is higher, by 0.6 units in $\mathrm{H}_{2} \mathrm{O}$ and by 0.9 units in $\mathrm{D}_{2} \mathrm{O}$. With the photophysical data and the effects of protonation in hand, we proceeded to study host-guest complexation phenomena to evaluate the potential of $\mathbf{4}$ and $\mathbf{5}$ to serve as novel fluorescent probes.

\section{Complexation with tetrakis( $N, N$ '-dimethylammoniomethyl)tetrahydroxycalix [4]arene (17)} We have recently introduced a new supramolecular sensor system for organic cations (e.g., cholines and carnitines), which is based on $\mathbf{1}$ and the cation receptor $p$-sulfonatocalix[4]arene (18), which displays a binding constant $\left(K_{\mathrm{a}}\right)$ of $1200 \mathrm{M}^{-1}$ at $\mathrm{pD} 7.4 .^{15}$ As an extension of this work, the sensor system has been refined by using the amino derivative $\mathbf{3}$ (in its ammonium form) which allows for additional Coulomb attractions with the four sulfonato groups in the cone conformation of 18. This is reflected in a strongly increased binding constant $\left(K_{\mathrm{a}}=6 \times 10^{4} \mathrm{M}^{-1}\right.$ for 3 at $\mathrm{pH} \mathrm{7.0),}{ }^{65}$ which improves the sensitivity of the sensor system. Conversely, we were interested in the ability of the cationic calixarene $\mathbf{1 7}$ to complex the novel DBO acids $\mathbf{4}$ and $\mathbf{5}$ in their anionic form and thereby devise potential sensor systems for anionic analytes.

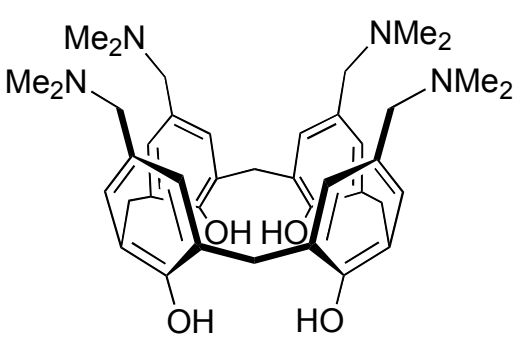

17

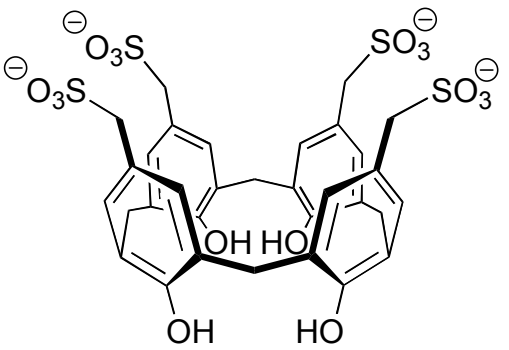

18

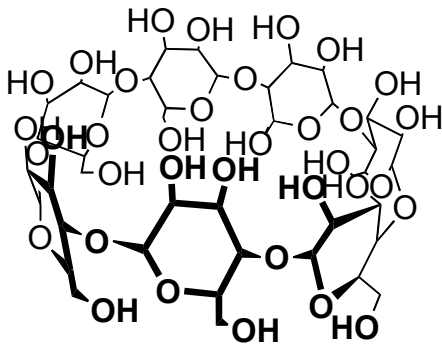

$\beta$-cyclodextrin

The host-guest complexation experiments were performed at $\mathrm{pH} 5.5$ where all ammonium groups of host $\mathbf{1 7}$ are expected to be protonated, but where the carboxylic acid groups of the azoalkanes (as guests) are deprotonated (Figure 1). Under these conditions, we found apparent binding constants by fluorescence titrations of $800 \mathrm{M}^{-1}$ for 4 and $1900 \mathrm{M}^{-1}$ for 5 (see Figure 2). Because the fluorescence quenching is partially related to a dynamic fluorescence 
quenching, ${ }^{15,17,18,22}$ which is expected to be more pronounced for $\mathbf{5}$ due to its longer fluorescence lifetime (vide supra), the binding constants derived from these titrations need to be considered as limiting maximum values $\left(<2000 \mathrm{M}^{-1}\right)$. Unfortunately, independent UV titrations could not be performed in order to obtain more accurate binding constants, because the strong and broad UV absorption band of $\mathbf{1 7}$ in the range of 320-380 nm prevented a monitoring of the weak UV absorption of the azo chromophore. $3,15,17$

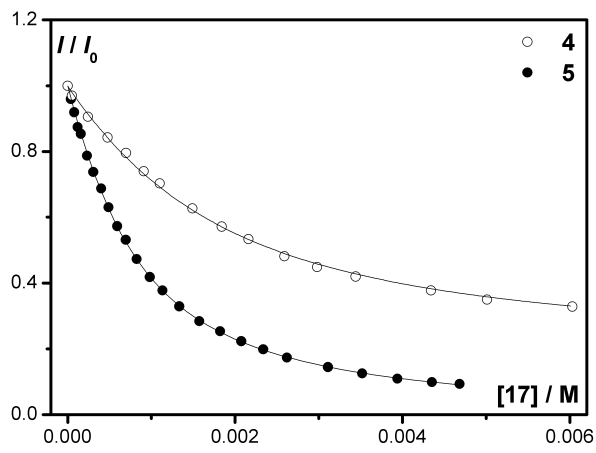

Figure 2. Fluorescence quenching of the DBO derivatives 4 (1 mM, open circles) and 5 ( $1 \mathrm{mM}$, filled circles) in $\mathrm{H}_{2} \mathrm{O}$ at $\mathrm{pH} 5.5$ upon addition of host 17. The solid lines correspond to the fitting curves for a 1:1 binding model.

Important to note, the estimated binding constants of $\mathbf{4}$ and $\mathbf{5}$ with host $\mathbf{1 7}\left(<2000 \mathrm{M}^{-1}\right.$ at $\mathrm{pH}$ 5.5) are unexpectedly low compared to the binding of $\mathbf{3}$ with host $18\left(K_{\mathrm{a}}=6 \times 10^{4} \mathrm{M}^{-1}\right)$. Indeed, ${ }^{1} \mathrm{H}$ NMR experiments revealed that $\mathbf{1 7}$ does not adopt a flexible cone conformation as $\mathbf{1 8}$ does, ${ }^{66}$ but instead a 1,3 -alternate conformation in $\mathrm{D}_{2} \mathrm{O}(\mathrm{pD}=6.0)$. This contrasts the cone conformation reported for 17 in $\mathrm{CDCl}_{3}{ }^{67}$ and independently predicted by molecular modeling studies in water, ${ }^{68}$ but is consistent with the 1,3-alternate conformation determined for the closely related tetrakis $\left(N, N^{\prime}, N^{\prime \prime}\right.$-trimethylammoniomethyl)tetramethoxy-calix[4]arene in water. ${ }^{69}$ Consequently, we attribute the low binding constant of $\mathbf{4}$ and $\mathbf{5}$ with $\mathbf{1 7}$ to the 1,3-alternate conformation of this host in water, because Coulomb attractions are reduced in the 1,3-alternate conformation compared to those in a cone conformation, where all four charged aryl groups can interact with the guest.

\section{Complexation with $\beta$-cyclodextrin}

The complexation behavior of cyclodextrins with DBO and bridgehead-substituted derivatives has been previously studied in great detail by steady-state and time-resolved fluorescence, UV spectrophotometry, induced circular dichroism (ICD), and NMR spectroscopy. ${ }^{17-23}$ We have now expanded the studies to the DBO acids 4 and 5. Complex formation was followed by ICD (see Table 2), where spectral effects accompanying host-guest complexation are exaggerated compared to those observed by UV spectrophotometry, ${ }^{18,21}$ and more straightforward to interpret 
than in fluorescence titrations, where dynamic quenching effects need to be considered as well. $^{15,17,18,22}$

Table 2. Binding constants of azoalkanes $1,{ }^{[1]} 4$, and 5 with $\beta$-cyclodextrin, determined by ICD

\begin{tabular}{rrrrrrr}
\hline & \multicolumn{2}{c}{$K_{\mathrm{a}}\left(\mathrm{M}^{-1}\right)$} & \multicolumn{2}{c}{$\theta(\mathrm{mdeg})^{[2]}$} & \multicolumn{2}{c}{$\Delta \varepsilon\left(\mathrm{cm}^{-1} \mathrm{M}^{-1}\right)^{[3]}$} \\
& \multicolumn{1}{c}{$\mathrm{pH} \mathrm{2.0}$} & \multicolumn{1}{c}{$\mathrm{pH} \mathrm{7.0}$} & $\mathrm{pH} \mathrm{2.0}$ & \multicolumn{1}{c}{$\mathrm{pH} \mathrm{7.0}$} & $\mathrm{pH} \mathrm{2.0}$ & $\mathrm{pH} \mathrm{7.0}$ \\
\hline $\mathbf{1}$ & \multicolumn{2}{c}{$920 \pm 100$} & \multicolumn{2}{c}{19.3} & \multicolumn{2}{c}{0.15} \\
$\mathbf{4}$ & $620 \pm 370$ & $26 \pm 13$ & $-4.2 \pm 0.5$ & $8.9 \pm 3.6$ & $-0.032 \pm 0.004$ & $0.067 \pm 0.027$ \\
$\mathbf{5}$ & $880 \pm 290$ & $120 \pm 60$ & $1.8 \pm 0.2$ & $3.2 \pm 0.9$ & $0.014 \pm 0.002$ & $0.024 \pm 0.007$ \\
\hline
\end{tabular}

[1] From ref. ${ }^{20}$ and ${ }^{22}$. ${ }^{[2]}$ Extrapolated to complete complexation from the fitted curves. ${ }^{[3]}$ Calculated as $\Delta \varepsilon=\theta /(32982 l c)$.

Interestingly, the binding constants of both $\mathbf{4}$ and $\mathbf{5}$ at $\mathrm{pH} 7.0$ are very low $\left(<120 \mathrm{M}^{-1}\right)$, which contrasts with previously reported binding constants of bicyclic bridgehead carboxysubstituted alkanes (e.g., for the bicyclo[2.2.2] octane analogue of 4 a binding constant of $9.7 \times$ $10^{4} \mathrm{M}^{-1}$ has been reported and $9.5 \times 10^{5} \mathrm{M}^{-1}$ for adamantanecarboxylic acid). ${ }^{70}$ This can be rationalized by considering the high intrinsic water solubility of bicyclic azoalkanes compared to bicyclic alkanes, which lowers the hydrophobic contribution to the driving force of complexation with cyclodextrins. ${ }^{22}$ The importance of guest hydrophobicity was also confirmed by the fact that the binding constants increased by ca. one order of magnitude when the carboxylic acid group was protonated (e.g., at $\mathrm{pH} 2.0$, Table 2). As previously observed for the two prototropic forms of the aminomethyl derivative 3 , the noncharged form has a higher affinity to cyclodextrins. ${ }^{22} \mathrm{~A}$ difference by one order of magnitude appears to be characteristic, which manifests itself also in a host-induced $\mathrm{p} K_{\mathrm{a}}$ shift, i.e., the $\mathrm{p} K_{\mathrm{a}}$ value of carboxylic acids included by $\beta$-cyclodextrin is expected to be one unit higher than in their uncomplexed state. ${ }^{16}$

The signs and magnitudes of the ICD signals (Figure 3) allow conclusions about the geometry of the host-guest complexes to be drawn, namely on the relative orientation of the guest to the host ("co-conformation"). The method has been exemplified in detail for bicyclic azoalkanes in previous studies, ${ }^{20-22}$ and the assignments were based on the rules of Harata ${ }^{71}$ and Kodaka. $^{72}$ For example, for cyclodextrin inclusion complexes of bridgehead-substituted azoalkanes, we have assumed frontal inclusion geometries (with the bridgehead hydrogen protruding into the cavity and the substituent interacting with the upper rim). While a negative ICD signal is a priori expected for a frontal co-conformation, positive signals can be interpreted in terms of a significant deviation (tilting) from the frontal geometry, presumably due to specific interactions of the functional groups of the guest with the hydroxyl network at the upper cyclodextrin rim. Accordingly, the observed (weak) ellipticities (Table 2) may be tentatively interpreted in terms of an accurately frontal geometry for azoalkane $\mathbf{4}$ at $\mathrm{pH} 2$ (negative sign), while for the other cases (positive signs) a tilted geometry is indicated (Scheme 3 ). The inversion of the ICD sign of azoalkane 4 at neutral and acidic $\mathrm{pH}$ (Figure 3 ) is reminiscent of the inversion 
in ICD sign previously observed for azoalkane $\mathbf{3}$ at neutral and alkaline $\mathrm{pH}^{22}$ Variations in hydrogen bonding interactions at the upper cyclodextrin rim have been held responsible for these subtle changes in the complex geometry.

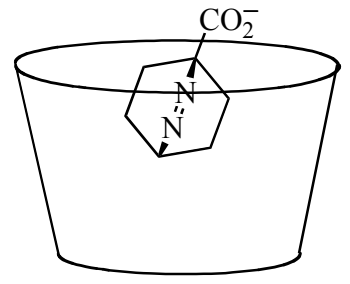

$\beta-\mathrm{CD} \cdot 4$ (pH 7)

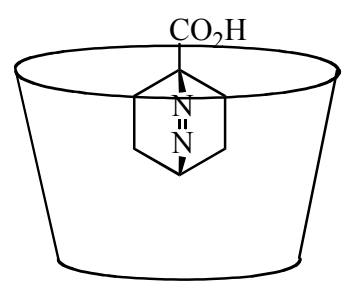

$\beta-\mathrm{CD} \cdot 4$ (pH 2)

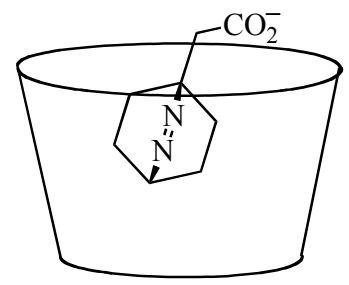

$\beta-\mathrm{CD} \cdot 5$ (pH 7)

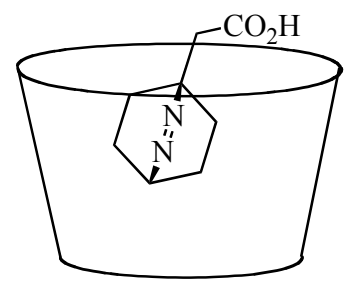

$\beta-\mathrm{CD} \cdot 5$ $(\mathrm{pH} 2)$

Scheme 1. Proposed structures (based on tentative ICD assignments) of the cyclodextrin complexes of azoalkanes $\mathbf{4}$ and $\mathbf{5}$ at $\mathrm{pH} 7.0$ and 2.0.

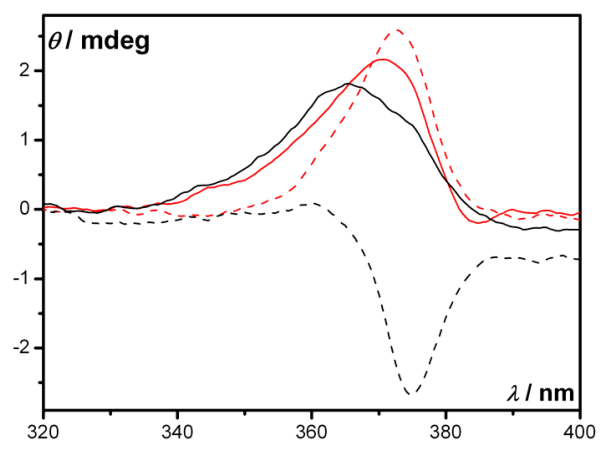

Figure 3. ICD spectra of azoalkanes $4(4 \mathrm{mM}$, black) and $5(4 \mathrm{mM}$, red) at $\mathrm{pH} 7.0$ (solid line) and $\mathrm{pH} 2.0$ (dashed) in $\mathrm{H}_{2} \mathrm{O}$ in the presence of $12 \mathrm{mM} \beta$-cyclodextrin.

\section{Experimental Section}

General Procedures. Time-resolved fluorescence spectroscopy was conducted by timecorrelated single photon counting (FLS920, Edinburgh Instruments) with a Picoquant picosecond 
pulsed diode laser $\left(\lambda_{\mathrm{exc}}=373 \mathrm{~nm}, \lambda_{\mathrm{em}}=450 \mathrm{~nm}\right.$, ca. $50 \mathrm{ps}$ pulsewidth $)$ for excitation. Fluorescence spectra were recorded with a Varian Eclipse spectrofluorometer $\left(\lambda_{\mathrm{exc}}=365\right.$ $\left.\mathrm{nm}, \lambda_{\mathrm{em}}=450 \mathrm{~nm}\right)$. UV spectroscopy was performed on a Varian Cary 4000 spectrophotometer. Circular dichroism spectra were recorded on a Jasco J-810 ( $0.5 \mathrm{~nm}$ resolution, 25 accumulations) by using a cyclodextrin solution for background correction. Photoreactions (also for photodecomposition quantum yield determinations) were carried out in a Luzchem LZC-4V photoreactor equipped with 14 Hitachi FL8BL-B UVA lamps $\left(\lambda_{\max , \mathrm{em}}=350 \mathrm{~nm}\right)$. NMR-spectra were recorded on a JEOL JNM-ECX400 working at $400 \mathrm{MHz}$ for ${ }^{1} \mathrm{H}$ and $100 \mathrm{MHz}$ for ${ }^{13} \mathrm{C}$ measurements. $\mathrm{pH}$ measurements were performed with a WTW 330i $\mathrm{pH}$ meter equipped with a WTW SenTix Mic glass electrode. Conversion to $\mathrm{pD}$ values was made on the basis of ref. ${ }^{73}$ (+ 0.40 units). X-ray analysis has been performed on a Bruker X8 APEX II CCD diffractometer with kappa geometry using $\operatorname{MoK} \alpha(\lambda=0.71073 \AA)$ radiation at $173(2) \mathrm{K}$. Semi-empirical computations were carried out by applying the AM1/UHF force field embedded within Hyperchem ver. 7.1 (Hypercube Inc., Gainesville, FL).

\section{Synthesis}

1-Hydroxycarbonyl-1,3-cyclohexadiene (9). The aldehyde 8 was prepared according to ref. ${ }^{44}$. $25.5 \mathrm{~g}(0.15 \mathrm{~mol})$ of silver nitrate were dissolved in $700 \mathrm{ml}$ water and added to a stirred solution of $12.0 \mathrm{~g}(0.30 \mathrm{~mol})$ sodium hydroxide in $700 \mathrm{ml}$ water. To the resulting grey suspension $5.4 \mathrm{~g}$ ( $0.05 \mathrm{~mol}$ ) of aldehyde 8 , dissolved in $15 \mathrm{ml}$ of THF, were added over the course of one hour. The mixture was stirred overnight at ambient temperature. After removal of THF under vacuum, the suspension was filtered and washed with hot water. After acidification with $2 \mathrm{~N} \mathrm{HCl}$ the organic acid was extracted with diethylether. The combined ether extracts were washed with water and dried over magnesium sulfate. After filtration and removal of the solvent, a pale, yellow oil was obtained that crystallized in the refrigerator. Recrystallization from ethanol/water (50/50) yielded $6.2 \mathrm{~g}$ (100\% conversion) of 9 as white to pale yellow crystals with identical physical properties to ref. ${ }^{45}$. The NMR spectra of the crude product showed various amounts of aromatized product (benzoic acid).

1-Hydroxycarbonyl-4-methyl-2,4,6-triaza-tricyclo[5.2.2.0 ${ }^{2.6}$ ] undec-8-ene-3,5-dione (10). A solution of $5 \mathrm{~g}$ ( $44.2 \mathrm{mmol})$ of MTAD in $100 \mathrm{ml}$ dichloromethane was added dropwise to a

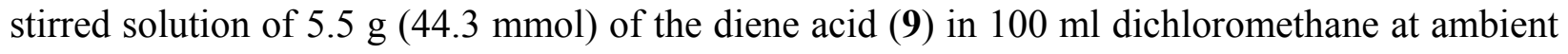
temperature. After about half of the MTAD solution had been added, the reaction mixture started to become cloudy and a white precipitate was formed. At the end of the addition, the pink color remained permanently (unreacted MTAD). The suspension was vacuum filtrated and washed with ethanol at ambient temperature. The remaining white powder was recrystallized from ethanol. Evaporation of the combined supernatant and washing liquids yielded a further fraction of crude cycloaddition product which was purified in the same way. The combined fractions of white crystalline powder gave $10.3 \mathrm{~g}(98 \%) \mathbf{1 0}$.

m.p.: $193^{\circ} \mathrm{C}$ 
${ }^{1} \mathrm{H}-\mathrm{NMR}$ (DMSO-d6): $\quad \delta 1.35-1.60(2 \mathrm{H}, \mathrm{m}), 2.00-2.30(2 \mathrm{H}, \mathrm{m}), 2.81(3 \mathrm{H}, \mathrm{s}), 4.79(1 \mathrm{H}, \mathrm{m})$, 6.42-6.48 (1H, m), 6.69-6.76 (1H, m)

${ }^{13}$ C-NMR (DMSO-d6): $\quad \delta 24.9,26.3,50.7,52.9,61.9,129.5,131.3,158.3,158.8,169.5$

Anal. calcd. for $\mathrm{C}_{10} \mathrm{H}_{11} \mathrm{~N}_{3} \mathrm{O}_{4}$ : C: $50.63 \% \quad \mathrm{H}: 4.67 \% \quad \mathrm{~N}: 17.71 \% \quad$ O: $26.98 \%$

Found: C: $50.71 \% \quad \mathrm{H}: 4.72 \% \quad \mathrm{~N}: 17.66 \% \mathrm{O}: 27.09 \%$

1-Hydroxycarbonyl-4-methyl-2,4,6-triaza-tricyclo[5.2.2.0 $\left.{ }^{\mathbf{2 . 6}}\right]$ undecan-3,5-dione (11). $10 \mathrm{~g}$ $(42.15 \mathrm{mmol})$ of the olefinic acid $\mathbf{1 0}$ were dissolved in $200 \mathrm{ml}$ dioxane in a normal pressure hydrogenation apparatus and $100 \mathrm{mg}$ of $5 \%$ palladium on carbon catalyst were added. The hydrogenation was conducted overnight until no more hydrogen was consumed. The reaction mixture was filtered through filter paper and additionally through a $1 \mathrm{~cm}$ layer of silica to remove traces of fine carbon particles. After removal of the solvent under vacuum a honey-like residue was obtained, which became a glassy solid upon standing in the refrigerator. Recrystallization from ethanol yielded $9.8 \mathrm{~g}(97 \%) \mathbf{1 1}$ as a white crystalline powder.

m.p.: $210^{\circ} \mathrm{C}$

${ }^{1} \mathrm{H}-\mathrm{NMR}$ (DMSO-d6): $\quad \delta$ 1.4-1.6 (2H, m), 1.6-1.9 (4H, m), 2.0-2.15 (2H, m), $3.11(3 \mathrm{H}, \mathrm{s})$, $4.34(1 \mathrm{H}, \mathrm{m}), 10.10-10.20(1 \mathrm{H}, \mathrm{br})$

${ }^{13}$ C-NMR (DMSO-d6): $\quad \delta$ 24.0, 27.8, 50.2, 60.0, 154.9, 156.7, 170.8, 175.8

Anal. calcd. for $\mathrm{C}_{10} \mathrm{H}_{13} \mathrm{~N}_{3} \mathrm{O}_{4}:$ C: $50.21 \% \mathrm{H}: 5.48 \%$ N: $17.56 \%$ O: $26.75 \%$

Found: C: $50.39 \% \mathrm{H}: 5.53 \%$ N: $17.52 \%$ O: 26.55 .

2,3-Diazabicyclo[2.2.2] oct-2-ene-1-carboxylic acid (4). $16.7 \mathrm{~g}(0.3 \mathrm{~mol}) \mathrm{KOH}$ pellets were dissolved in $100 \mathrm{ml} i$-propanol and $5 \mathrm{~g}(20.09 \mathrm{mmol})$ of 11 were added under inert atmosphere. The mixture became clear upon heating to reflux. After about half an hour, a white precipitate formed (presumably potassium carbonate). Refluxing under inert atmosphere was continued for 2 days. The mixture was allowed to cool to ambient temperature and transferred into a beaker. The beaker was left open under air for 3 days (stirring during the first $24 \mathrm{~h}$ ) to oxidize the intermediary hydrazine to the corresponding azo compound and to evaporate $i$-propanol. To the resulting white solid, $25 \% \mathrm{HCl}$ was added dropwise $\left(\mathrm{CO}_{2}\right.$-evolution!) under cooling with ice until a clear solution was formed with neutral $\mathrm{pH}$. Further addition of $\mathrm{HCl}$ (up to $\mathrm{pH}$ ca. 1) afforded a white microcrystalline precipitate. The liquid was removed carefully with a pipette and the residue was washed twice with a small amount of distilled water to remove remaining $\mathrm{KCl}$ traces. After the solid was dried under vacuum a recrystallization from ethyl acetate with hot filtration was performed. Suction filtration and drying under air yielded $1.23 \mathrm{~g}(42 \%)$ of 4 as white crystals. An additional slow crystallization from ethanol produced single crystals suitable for X-ray structure analysis. The resulting structure is shown in Figure 4.

m.p.: $142{ }^{\circ} \mathrm{C}($ dec.)

${ }^{1} \mathrm{H}-\mathrm{NMR}\left(\mathrm{CDCl}_{3}\right): \quad \delta 1.30-1.50(4 \mathrm{H}, \mathrm{m}), 1.60-1.80(2 \mathrm{H}, \mathrm{m}), 1.95-2.15(2 \mathrm{H}, \mathrm{m}), 5.33(1 \mathrm{H}, \mathrm{m})$, 6.20-7.80 (1H, br)

${ }^{13} \mathrm{C}-\mathrm{NMR}\left(\mathrm{CDCl}_{3}\right): \quad \delta 20.9(\mathrm{t}), 24.5(\mathrm{t}), 62.3(\mathrm{~d}), 69.6(\mathrm{~s}), 175.1(\mathrm{~s})$

Anal. calcd. for $\mathrm{C}_{7} \mathrm{H}_{10} \mathrm{~N}_{2} \mathrm{O}_{2}$ : C: $54.54 \% \mathrm{H}: 6.54 \% \quad \mathrm{~N}: 18.17 \%$ O: $20.76 \%$

Found: $\quad$ C: $54.53 \% \mathrm{H}: 6.49 \%$ N: $18.19 \%$ O: $20.94 \%$ 

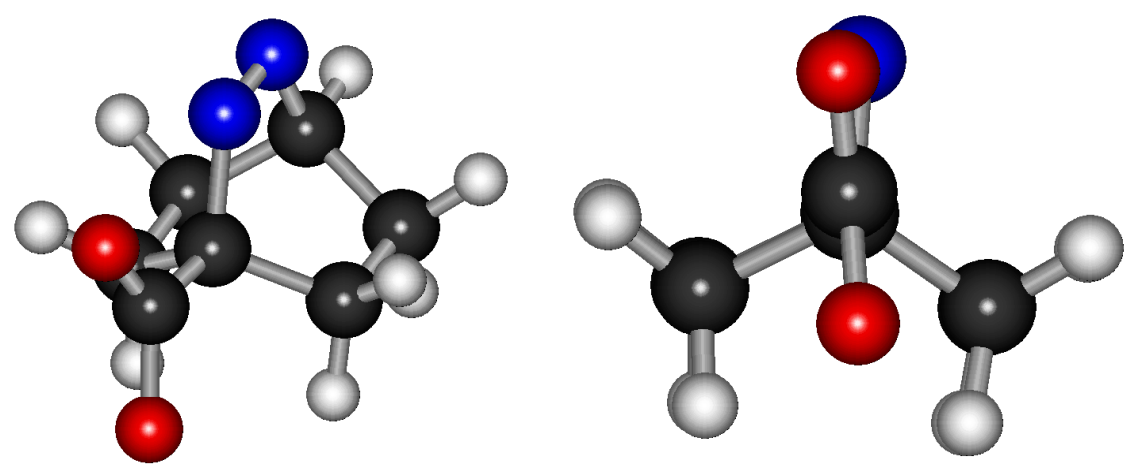

Figure 4. Different views of the X-ray crystal structure of the DBO acid 4.

1-Cyanomethyl-2,3-diaza-bicyclo[2.2.2] oct-2-ene (13). To a solution of $5.89 \mathrm{~g}$ (20 mmol) of the tosylate 12 (prepared according to ref. ${ }^{30}$ ) in $100 \mathrm{ml}$ dry DMSO $4.9 \mathrm{~g}(0.1 \mathrm{~mol})$ sodium cyanide (dried at $110^{\circ} \mathrm{C}$ under vacuum) were added in one portion and the resulting suspension was warmed up until it became clear and heated for an additional $24 \mathrm{~h}$ under dry nitrogen to $110^{\circ} \mathrm{C}$. The warm reaction mixture was poured into $100 \mathrm{ml}$ of ice-water and extracted with diethylether. After drying with sodium sulfate, the solvent was evaporated to give the crude nitrile. Recrystallization from $n$-hexane afforded $2.03 \mathrm{~g}(68 \%)$ of nitrile 13 in the form of long colorless needles. Further extraction of the aqueous phase with dichloromethane allowed the recovery of unreacted tosylate.

m.p.: $103{ }^{\circ} \mathrm{C}$

${ }^{1} \mathrm{H}-\mathrm{NMR}\left(\mathrm{CDCl}_{3}\right): \quad \delta 1.15-1.3(2 \mathrm{H}, \mathrm{m}), 1.35-1.45(2 \mathrm{H}, \mathrm{m}), 1.60-1.85(4 \mathrm{H}, \mathrm{m}), 3.16(2 \mathrm{H}, \mathrm{s})$, $5.21(1 \mathrm{H}, \mathrm{m})$

${ }^{13} \mathrm{C}-\mathrm{NMR}\left(\mathrm{CDCl}_{3}\right): \quad \delta 21.7(\mathrm{t}), 25.8(\mathrm{t}), 28.2(\mathrm{~d}), 61.5(\mathrm{~s}), 64.5(\mathrm{t}), 117.2(\mathrm{~s})$

Anal. calcd. for $\mathrm{C}_{8} \mathrm{H}_{11} \mathrm{~N}_{3}$ : C: $64.40 \% \mathrm{H}: 7.43 \% \quad \mathrm{~N}: 28.16 \%$

Found: C: $64.36 \% \mathrm{H}: 7.30 \% \quad \mathrm{~N}: 28.16 \%$

2-(2,3-Diazabicyclo[2.2.2]oct-2-en-1-yl)acetic acid (5). $1.0 \mathrm{~g}(6.7 \mathrm{mmol})$ of the nitrile 13 were mixed with $0.5 \mathrm{~g}$ sodium hydroxide in $10 \mathrm{ml}$ water together with some drops of ethanol. After heating to $90{ }^{\circ} \mathrm{C}$ for eight hours the hydrolysis was complete. Upon acidification with $25 \%$ hydrochloric acid a white precipitate was formed. Vacuum filtration and recrystallization from ethanol yielded $1.09 \mathrm{~g}(97 \%)$ of the acid 5 in the form of white flat plates.

m.p.: $139{ }^{\circ} \mathrm{C}$

${ }^{1} \mathrm{H}-\mathrm{NMR}\left(\mathrm{CDCl}_{3}\right): \delta 1.18-1.27(2 \mathrm{H}, \mathrm{m}), 1.35-1.45(2 \mathrm{H}, \mathrm{m}), 1.6-1.83(4 \mathrm{H}, \mathrm{m}), 3.16(2 \mathrm{H}, \mathrm{s}), 5.21$ $(1 \mathrm{H}, \mathrm{m}), 8.78(1 \mathrm{H}, \mathrm{s})$

${ }^{13} \mathrm{C}-\mathrm{NMR}\left(\mathrm{CDCl}_{3}\right): \delta 22.0(\mathrm{t}), 26.1(\mathrm{t}), 43.5(\mathrm{~d}), 61.8(\mathrm{~s}), 65.7(\mathrm{t}), 175.0(\mathrm{~s})$

Anal. calcd. for $\mathrm{C}_{8} \mathrm{H}_{12} \mathrm{~N}_{2} \mathrm{O}_{2}$ : C: $57.13 \% \mathrm{H}: 7.19 \% \quad \mathrm{~N} 354$ 16.66\% O: $19.03 \%$

Found: C: $57.04 \% \mathrm{H}: 7.21 \%$ N: $16.60 \%$ O: $19.27 \%$ 


\section{Acknowledgements}

This work was performed within the graduate program "Nanomolecular Science" at Jacobs University Bremen. We thank PD Dr. Jürgen Schatz (Universität Ulm) for a sample of tetrakis( $N, N$ '-dimethylammoniomethyl)-tetrahydroxycalix[4]arene, Dr. Michael Dickman (Jacobs) for the X-ray analysis of 4, and Upakul Deka as well as Mara Florea for preliminary photophysical measurements. A. Hennig also thanks Hoffmann-La Roche for a Ph.D. stipend.

\section{References}

1. Adam, W.; De Lucchi, O. Angew. Chem. Int. Ed. 1980, 19, 762.

2. Engel, P. S. Chem. Rev. 1980, 80, 99.

3. Nau, W. M.; Pischel, U. Photoreactivity of n, $\pi^{*}$ excited azoalkanes and ketones. In Organic Photochemistry and Photophysics, Ramamurthy, V.; Schanze, K. S., Eds. CRC Press: Boca Raton, FL, 2005; Vol. 14, pp 75-129.

4. Mascitti, V.; Corey, E. J. J. Am. Chem. Soc. 2004, 126, 15664.

5. Adam, W.; Fröhlich, L.; Nau, W. M. J. Am. Chem. Soc. 1993, 115, 9824.

6. Adam, W.; Fröhlich, L.; Nau, W. M.; Korth, H.-G.; Sustmann, R. Angew. Chem. 1993, 105, 1383.

7. Nau, W. M.; Harrer, H. M.; Adam, W. J. Am. Chem. Soc. 1994, 116, 10972.

8. Adam, W.; van Berneveld, C.; Bottle, S. E.; Engert, H.; Hanson, G. R.; Harrer, H. M.; Heim, C.; Nau, W. M.; Wang, D. J. Am. Chem. Soc. 1996, 118, 3974.

9. Nau, W. M. Angew. Chem. Int. Ed. 1997, 36, 2445.

10. Adam, W.; Harrer, H. M.; Kita, F.; Nau, W. M. Adv. Photochem. 1998, 24, 205.

11. Abe, M.; Adam, W.; Heidenfelder, T.; Nau, W. M.; Zhang, X. Y. J. Am. Chem. Soc. 2000, $122,2019$.

12. Adam, W.; Diedering, M.; Trofimov, A. V. J. Am. Chem. Soc. 2004, 124, 5427.

13. Adam, W.; Trofimov, A. V., Photomechanistic Aspects of Bicyclic Azoalkanes: Triplet States, Photoreduction, and Double Inversion. In CRC Handbook of Organic Photochemistry and Photobiology, 2nd Edn.; Horspool, W.; Lenci, F., Eds. CRC Press: Boca Raton, 2004; pp 93-1.

14. Nau, W. M.; Wang, X. J. ChemPhysChem 2002, 3, 393.

15. Bakirci, H.; Nau, W. M. Adv. Funct. Mat. 2006, 16, 237.

16. Bakirci, H.; Koner, A. L.; Schwarzlose, T.; Nau, W. M. Chem. Eur. J. 2006, 12, 4799.

17. Nau, W. M.; Zhang, X. Y. J. Am. Chem. Soc. 1999, 121, 8022.

18. Bakirci, H.; Nau, W. M. J. Photochem. Photobiol., A 2005, 173, 340.

19. Bakirci, H.; Koner, A. L.; Nau, W. M. J. Org. Chem. 2005, 70, 9960.

20. Zhang, X. Y.; Nau, W. M. Angew. Chem. Int. Ed. 2000, 39, 544.

21. Bakirci, H.; Zhang, X. Y.; Nau, W. M. J. Org. Chem. 2005, 70, 39. 
22. Zhang, X. Y.; Gramlich, G.; Wang, X. J.; Nau, W. M. J. Am. Chem. Soc. 2002, 124, 254.

23. Bakirci, H.; Nau, W. M. J. Org. Chem. 2005, 70, 4506.

24. Wang, X. J.; Nau, W. M. J. Am. Chem. Soc. 2004, 126, 808.

25. Pischel, U.; Huang, F.; Nau, W. M., Photochem. Photobiol. Sci. 2004, 3, 305.

26. Gramlich, G.; Zhang, J. Y.; Winterhalter, M.; Nau, W. M. Chem. Phys. Lipids 2001, 113, 1.

27. Gramlich, G.; Zhang, J. Y.; Nau, W. M. J. Am. Chem. Soc. 2002, 124, 11252.

28. Gramlich, G.; Zhang, J. Y.; Nau, W. M. J. Am. Chem. Soc. 2004, 126, 5482.

29. Nau, W. M. J. Am. Chem. Soc. 1998, 120, 12614.

30. Hudgins, R. R.; Huang, F.; Gramlich, G.; Nau, W. M. J. Am. Chem. Soc. 2002, 124, 556.

31. Huang, F.; Nau, W. M. Angew. Chem. Int. Ed. 2003, 42, 2269.

32. Huang, F.; Hudgins, R. R.; Nau, W. M. J. Am. Chem. Soc. 2004, 126, 16665.

33. Huang, F.; Nau, W. M. Res. Chem. Intermed. 2005, 31, 717.

34. Sahoo, H.; Hennig, A.; Nau, W. M. Int. J. Photoenergy 2006, 2006, Article ID 89638, 9 pages, doi: 10.1155/IJP/2006/89638.

35. Hennig, A.; Roth, D.; Enderle, T.; Nau, W. M. ChemBioChem 2006, 7, 733.

36. Bakirci, H.; Nau, W. M., unpublished results.

37. Cohen, S. G.; Zand, R. J. Am. Chem. Soc. 1962, 84, 586.

38. Adam, W.; Nikolaus, A.; Sauer, J. J. Org. Chem. 1999, 64, 3695.

39. Martin, H.-D.; Hekman, M. Angew. Chem. Int. Ed. 1976, 15, 431.

40. Christl, M.; Freund, S.; Henneberger, H.; Kraft, A.; Hauck, J.; Irngartinger, H. J. Am. Chem. Soc. 1988, 110, 3263.

41. Engel, P. S.; Horsey, D. W.; Scholz, J. N.; Karatsu, T.; Kitamura, A. J. Phys. Chem. 1992, 96, 7524.

42. Sauer, J.; Bäuerlein, P.; Ebenbeck, W.; Gousetis, C.; Sichert, H.; Troll, T.; Utz, F.; Wallfahrer, U. Eur. J. Org. Chem. 2001, 2629.

43. Dittmar, W.; Heinrichs, G.; Steigel, A.; Troll, T.; Sauer, J. Tetrahedron Lett. 1970, 11, 1623.

44. Hünig, S.; Kahanek, H., Chem. Ber. 1957, 90, 238.

45. Blanc, P. Y., Helv. Chim. Acta 1961, 44, 1.

46. Tietze, L.-F.; Eicher, T. Reaktionen und Synthesen; Thieme: Stuttgart, New York, 1981.

47. Overberger, C. G.; Lapkin, M. J. Am. Chem. Soc. 1955, 77, 4651.

48. Engel, P. S.; Nalepa, C. J.; Horsey, D. W.; Keys, D. E.; Grow, R. T. J. Am. Chem. Soc. 1983, 105, 7102 .

49. Ingold, K. U.; Paul, T.; Young, M. J.; Doiron, L. J. Am. Chem. Soc. 1997, 119, 12364.

50. Carey, F. A.; Sundberg, R. J., Organische Chemie. VCH: Weinheim, 1995; p 275.

51. Mohanty, J.; Nau, W. M. Photochem. Photobiol. Sci. 2004, 3, 1026.

52. Nau, W. M.; Greiner, G.; Rau, H.; Wall, J.; Olivucci, M.; Scaiano, J. C. J. Phys. Chem. A 1999, 103, 1579.

53. Engel, P. S.; Horsey, D. W.; Keys, D. E.; Nalepa, C. J.; Soltero, L. R. J. Am. Chem. Soc. 1983, 105, 7108 .

54. Chen, H.; Li, S. J. Am. Chem. Soc. 2005, 127, 13190. 
55. Nau, W. M.; Greiner, G.; Wall, J.; Rau, H.; Olivucci, M.; Robb, M. A. Angew. Chem. Int. Ed. 1998, 37, 98 .

56. Dube, M. F.; Timberlake, J. W. Tetrahedron 1980, 36, 1753.

57. Adam, W.; Fragale, G.; Klapstein, D.; Nau, W. M.; Wirz, J. J. Am. Chem. Soc. 1995, 117, 12578.

58. Luedtke, A.; Meng, K.; Timberlake, J. W. Tetrahedron Lett. 1987, $28,4255$.

59. Creary, X.; Mehrsheikh-Mohammadi, M. E.; McDonald, S. J. Org. Chem. 1987, 52, 3254.

60. Ma, J.; Chan, T.-H. Tetrahedron Lett. 1998, 39, 2499.

61. Adlington, R. M.; Barrett, A. G. M. J. Chem. Soc. Perkin Trans. 1 1981, 2848.

62. Kirmse, W.; Sandkuehler, P. Liebigs Ann. Chem. 1981, 8, 1394.

63. Wenthold, P. G.; Squires, R. R. J. Am. Chem. Soc. 1994, 116, 11890.

64. Klapstein, D.; Pischel, U.; Nau, W. M. J. Am. Chem. Soc. 2002, 124, 11349.

65. Bakirci, H.; Koner, A. L.; Dickmann, M. H.; Kortz, U.; Nau, W. M. Angew. Chem. Int. Ed. 2006, 45, 7400 .

66. Nagasaki, T.; Sisido, K.; Arimura, T.; Shinkai, S. Tetrahedron 1992, 48, 797.

67. Gutsche, C. D.; Nam, K. C. J. Am. Chem. Soc. 1988, 110, 6153.

68. Baur, M.; Frank, M.; Schatz, J.; Schildbach, F. Tetrahedron 2001, 57, 6985.

69. Shi, Y.; Schneider, H.-J. J. Chem. Soc. Perkin Trans. 2 1999, 1797.

70. Eftink, M. R.; Andy, M. L.; Bystrom, K.; Perlmutter, H. D.; Kristol, D. S. J. Am. Chem. Soc. 1989, 111, 6765 .

71. Harata, K.; Uedaira, H. Bull. Chem. Soc. Jpn. 1975, 48, 375.

72. Kodaka, M. J. Am. Chem. Soc. 1993, 115, 3702.

73. Glasoe, P. K.; Long, F. A. J. Phys. Chem. 1960, 64, 188. 